Supporting Information

\title{
[3]Rotaxane-Porphyrin Conjugate as a Novel Supramolecular Host for Fullerenes
}

\author{
Jean-Sébastien Marois, Katy Cantin, Amélie Desmarais and Jean-François Morin* \\ Department of Chemistry and Centre de recherche en science et ingénierie des macromolécules, \\ Université Laval, Québec, Canada G1K 7P4 \\ Jean-francois.morin@chm.ulaval.ca
}

\section{Table of Contents}

1. Experiment Details for the Complexation Study of Tweezer 1 with Fullerenes

2. Experimental data, ${ }^{1} \mathrm{H}$ and ${ }^{13} \mathrm{C}$ NMR spectra for compound $\mathbf{1}$.

3. Experimental data for compounds 5-6, 8, 10-11

4. ${ }^{1} \mathrm{H}$ and ${ }^{13} \mathrm{C}$ NMR spectra for compounds 5-6, 8, 10-11

5. References 


\section{Experiment Details for the Complexation Study of Tweezer 1 with}

\section{Fullerenes}

\section{General Procedure}

$\mathrm{UV}$-vis titration experiments were carried out with solutions of tweezer $1\left(1 \times 10^{-6}\right.$ to $\left.2 \times 10^{-6} \mathrm{M}\right)$ in toluene or different mixtures of acetonitrile/toluene $(3 \mathrm{~mL})$ in a quartz cuvette $(1 \mathrm{~cm}$ path length). Fullerene $\left(\mathrm{C}_{60}, \mathrm{C}_{70}\right.$ or $\left.\mathrm{C}_{84}\right)$ was added in aliquots of 10 to $30 \mu \mathrm{L}$ from stock solutions in toluene $\left(7.5 \times 10^{-5}\right.$ to $\left.2.4 \times 10^{-3} \mathrm{M}\right)$ to both the blank and sample cells. The absorbance of the Soret band $(419 \mathrm{~nm})$ was recorded after each addition and corrected by a dilution factor. A plot of $\Delta \mathrm{A}$ versus [fullerene] was carried out and the binding constant $\left(\mathrm{K}_{\mathrm{a}}\right)$ and the absorbance at saturation of the binding sites $\left(\Delta \mathrm{A}_{\infty}\right)$ were evaluated by non-linear curve fitting using the

equation: $\Delta \mathrm{A}=\frac{\Delta \mathrm{A}_{\infty}\left(\left(1+\mathrm{K}_{\mathrm{a}}[F]+[T] K_{a}\right)-\sqrt{\left.\left(1+K_{a}[F]+[T] K_{a}\right)^{2}-4 K_{a}^{2}[F][T]\right)}\right.}{2 \mathrm{~K}_{\mathrm{a}}[T]}$

where $\Delta \mathrm{A}=\mathrm{A}-\mathrm{A}_{0},[\mathrm{~T}]$ is the concentration of the tweezer $\mathbf{1}$ solution and $[\mathrm{F}]$ is the concentration of the fullerene solution. ${ }^{1}$

Fluorescence titration experiments were carried out with a solution of tweezer $1\left(2 \times 10^{-7} \mathrm{M}\right)$ in toluene of different mixtures of acetonitrile/toluene $(3 \mathrm{~mL})$ in a quartz cuvette $(1 \mathrm{~cm}$ path length). The solution was excited at the isosbestic point of the complex (429 nm, determined by $\mathrm{UV}$-vis titration) and the fluorescent emission intensity was monitored at $654 \mathrm{~nm}$. Fullerene $\left(\mathrm{C}_{70}\right.$ or $\left.\mathrm{C}_{84}\right)$ was added in aliquots of $10 \mu \mathrm{L}$ from stock solutions in toluene $\left(7.5 \times 10^{-5}\right.$ to $3.0 \times 10^{-4}$ M) and the emission intensity recorded after each addition. A plot of $\Delta \mathrm{I}$ versus [fullerene] was 
carried out and the binding constant $\left(\mathrm{K}_{\mathrm{a}}\right)$ and the intensity at saturation of the binding sites $\left(\Delta \mathrm{I}_{\infty}\right)$ were evaluated by non-linear curve fitting using the same equation as above. 


\section{$\mathrm{C}_{60}$ in toluene (UV-vis)}

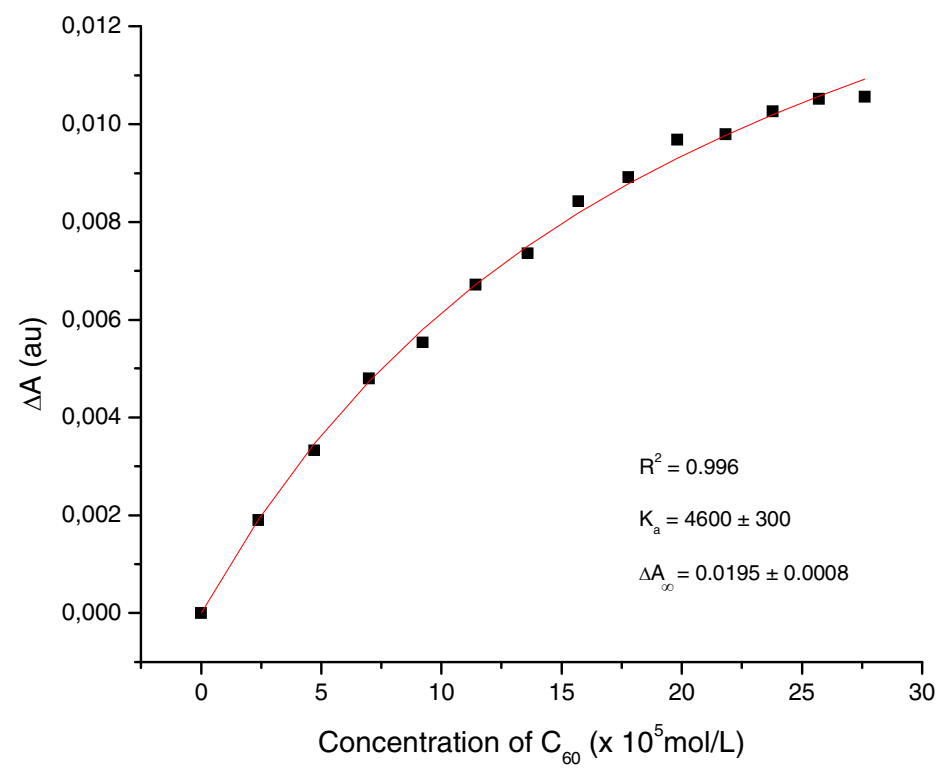

\section{$\mathrm{C}_{70}$ in toluene (UV-vis)}

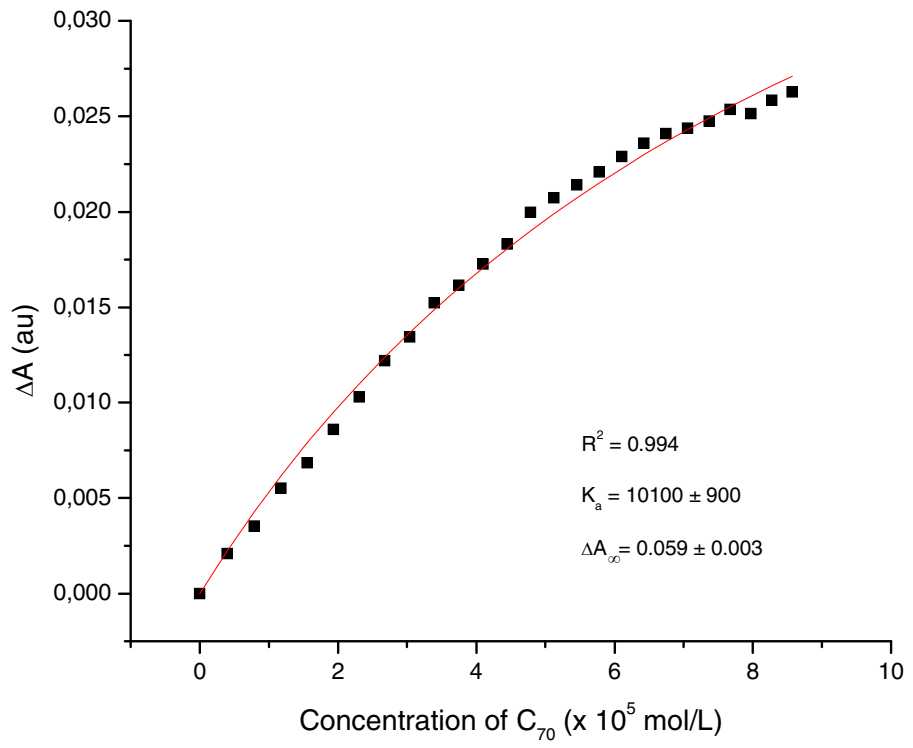




\section{$\mathrm{C}_{70}$ in MeCN/Toluene 1:1 (UV-vis)}

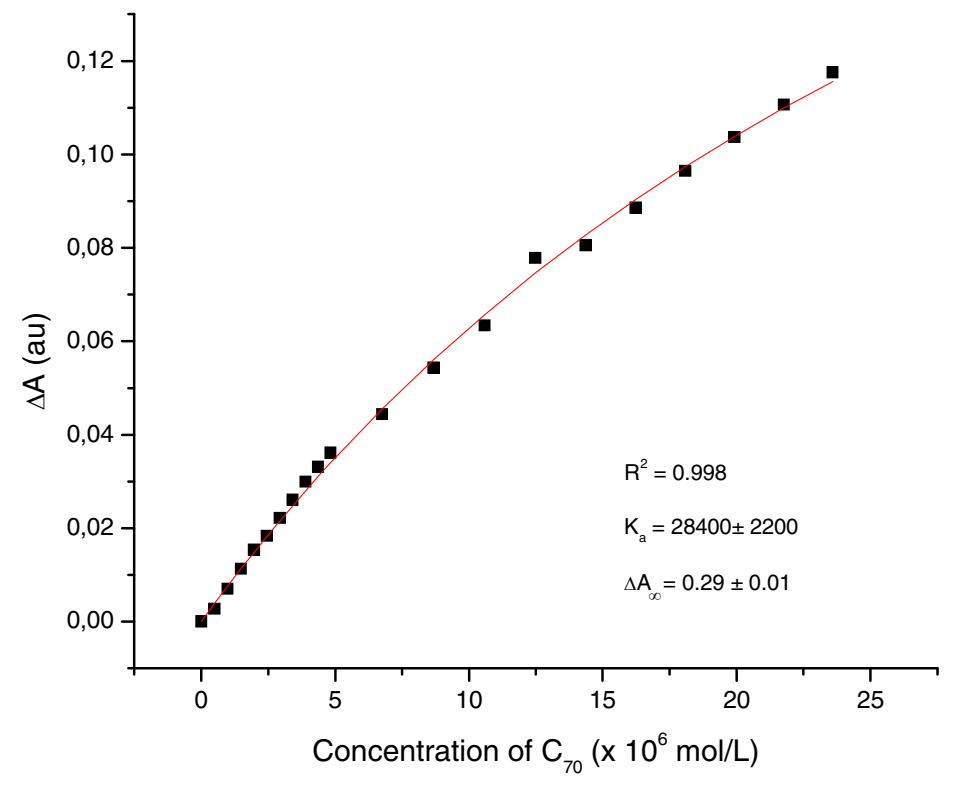

\section{$\mathrm{C}_{70}$ in MeCN/Toluene 3:2 (UV-vis)}

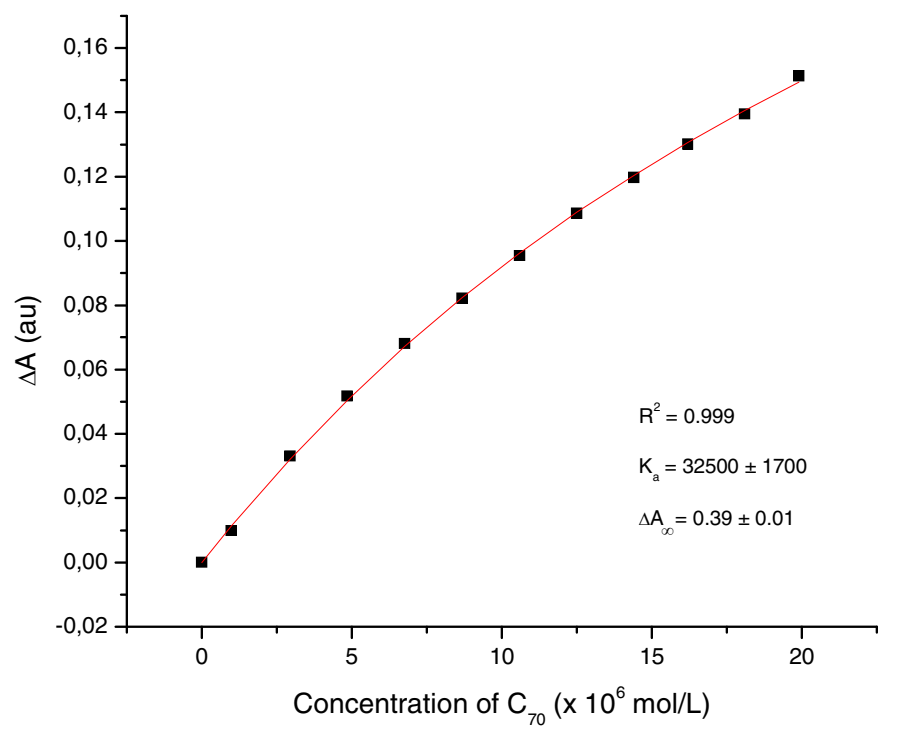


$\mathrm{C}_{70}$ in MeCN/Toluene 3:2 (fluo)

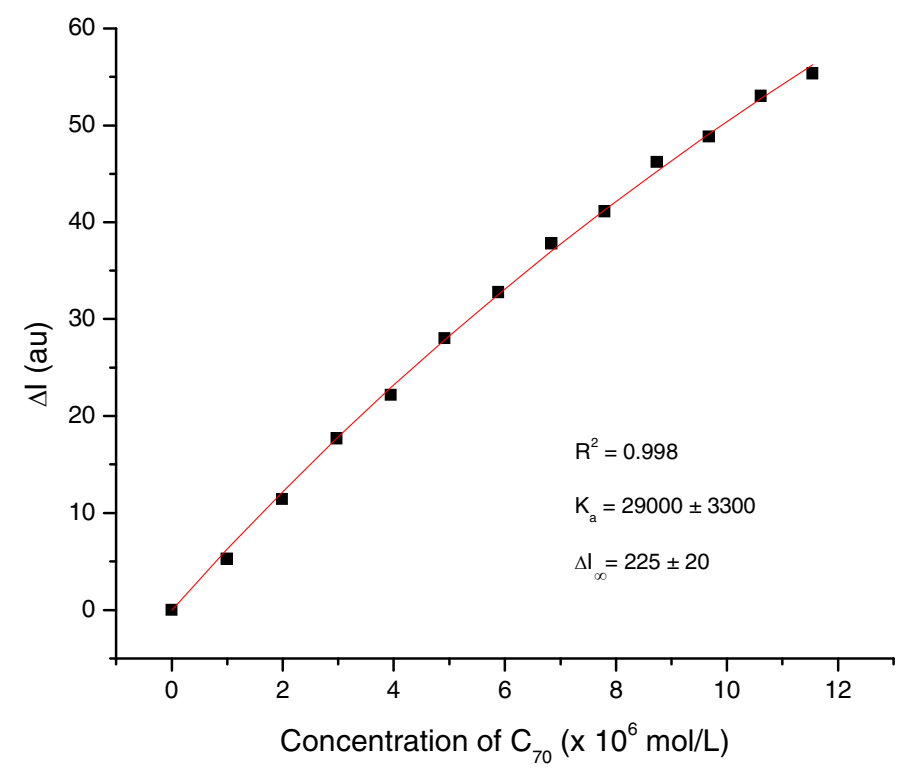

$\mathrm{C}_{84}$ in MeCN/Toluene 3:2 (UV-vis)

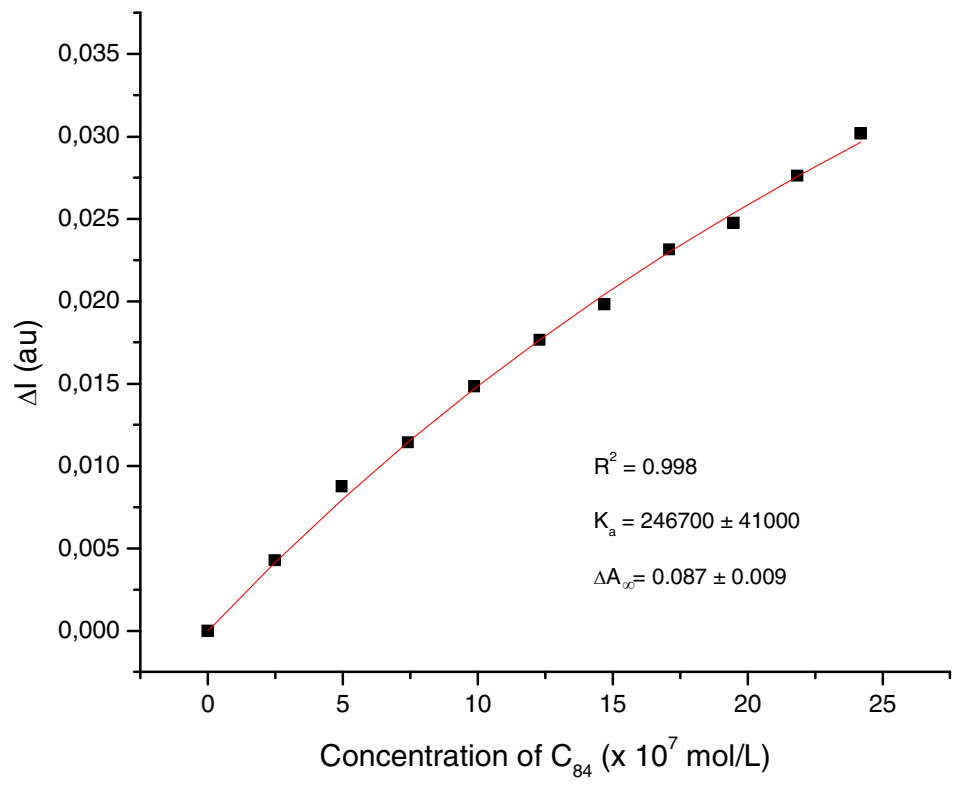


$\mathrm{C}_{84}$ in MeCN/Toluene 3:2 (fluo)

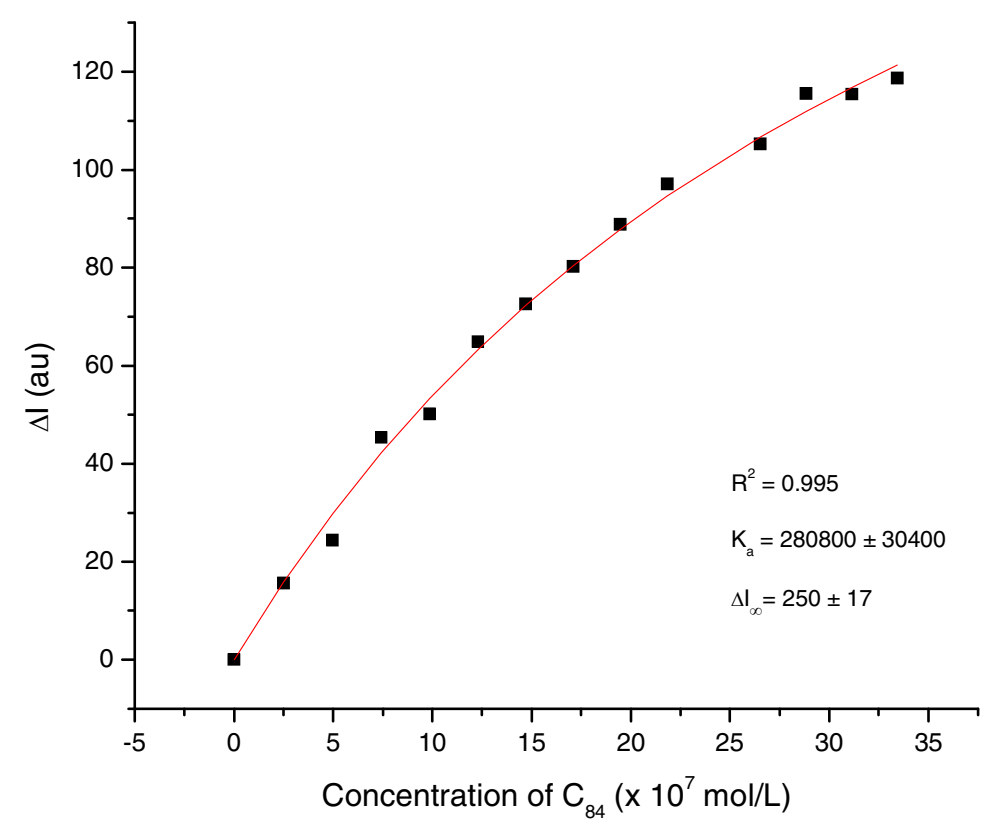

Tweezer 1 - Cu-porphyrin comparison (UV-vis)

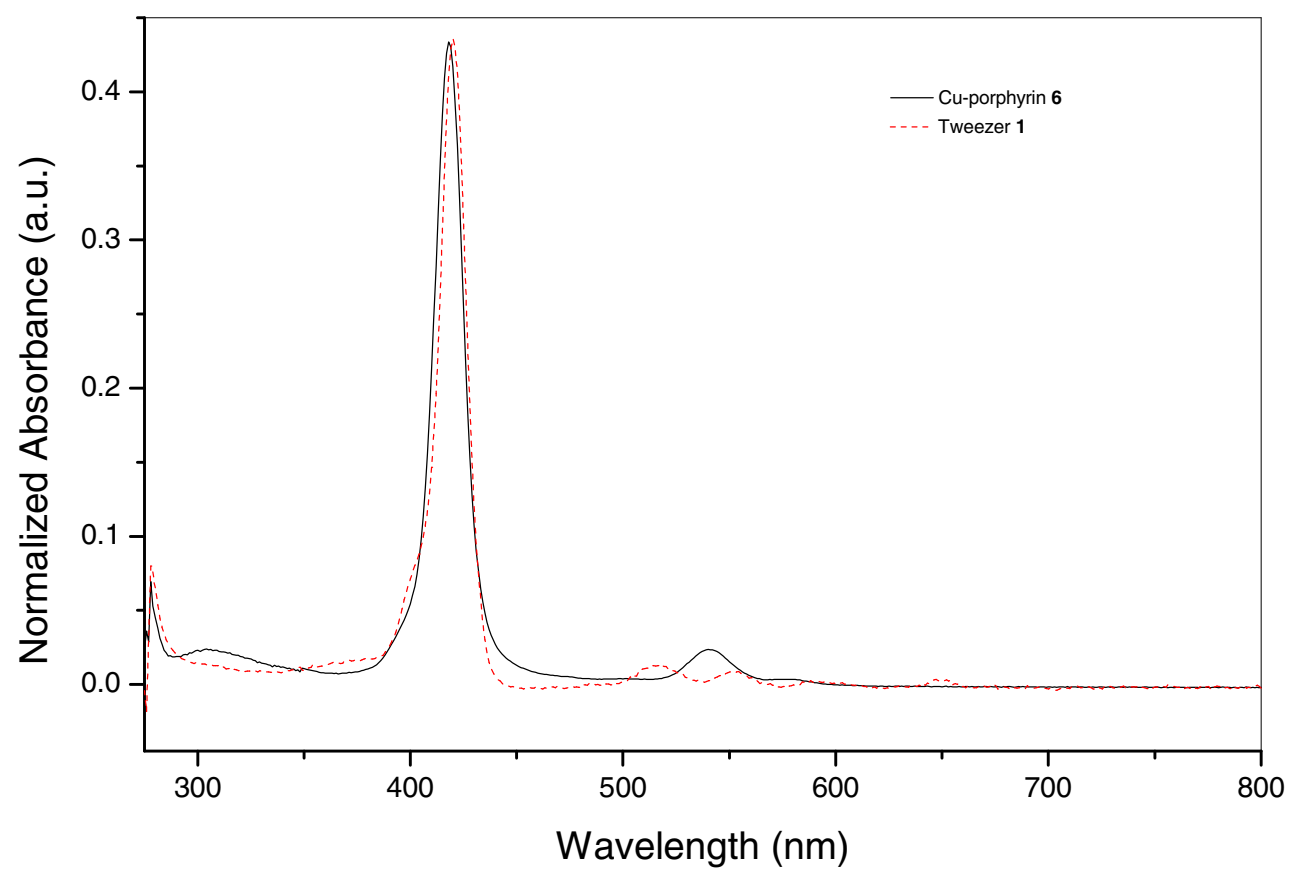


Job Plot for the complexation of $\mathrm{C}_{60}$ with 1 in benzene-d ${ }_{6}$ (NMR)

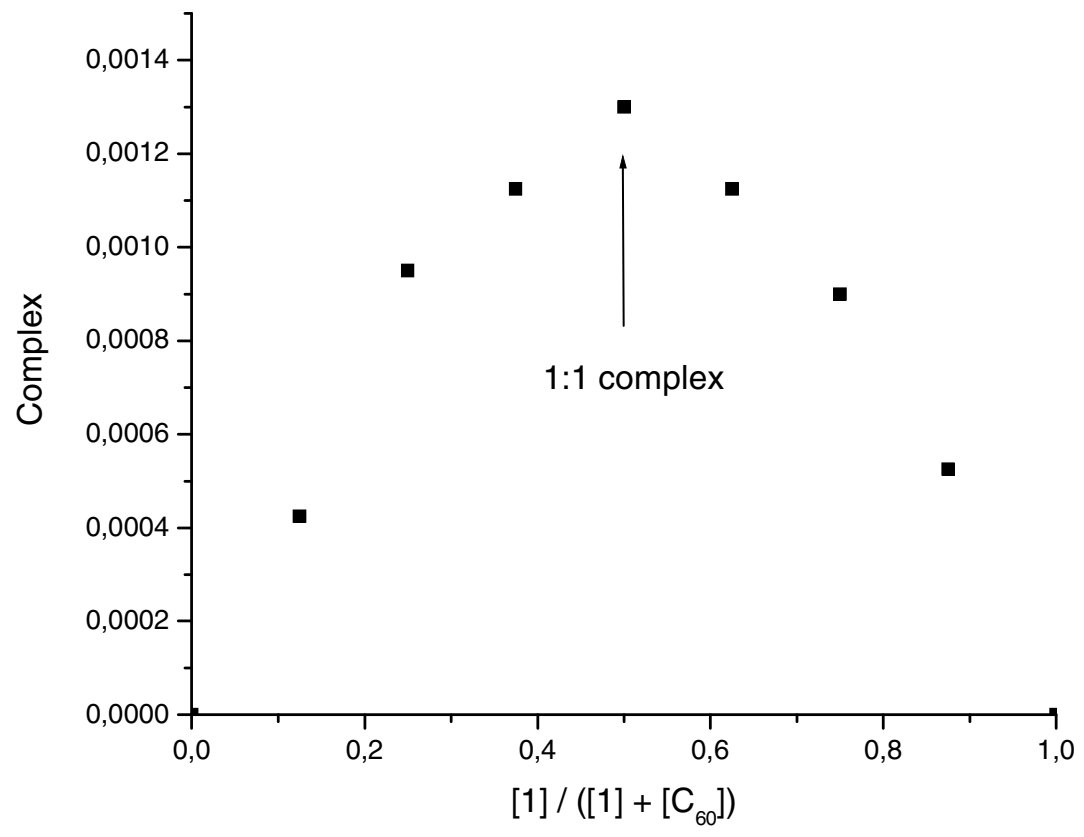

Job Plot for the complexation of $\mathrm{C}_{70}$ with 1 in benzene-d ${ }_{6}$ (NMR)

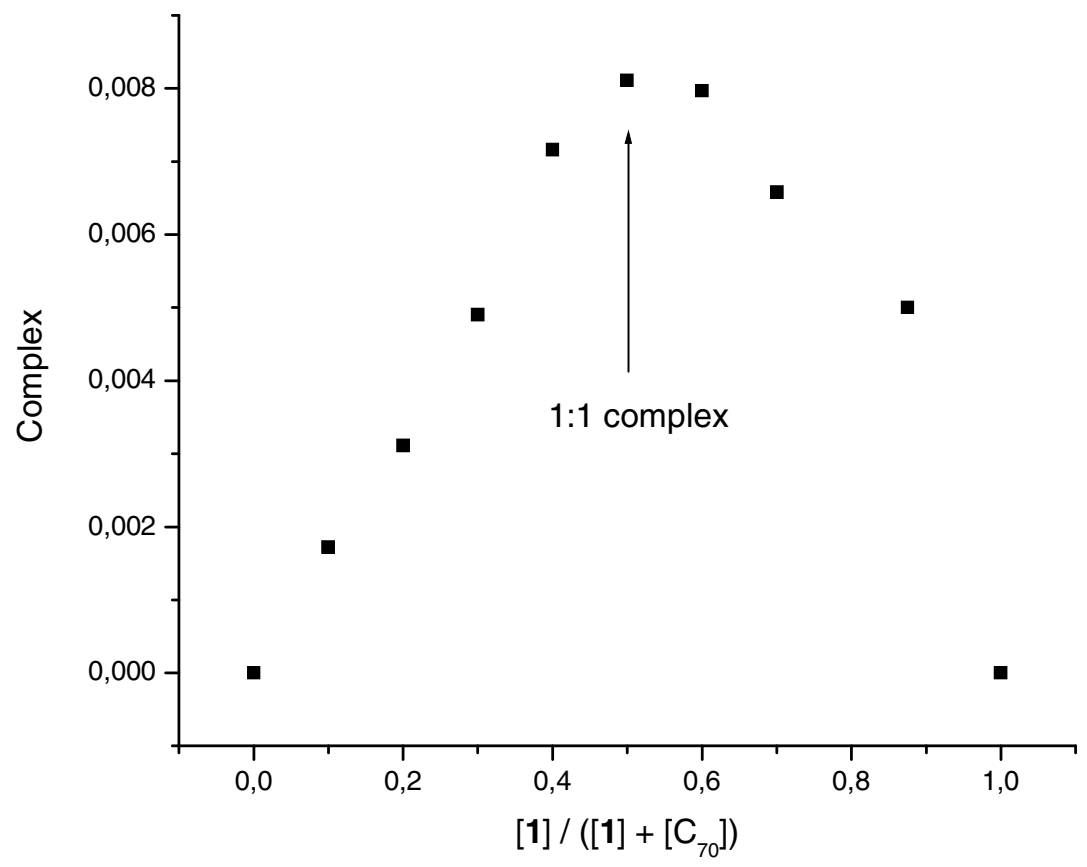




\section{Experimental data, ${ }^{1} \mathrm{H}$ and ${ }^{13} \mathrm{C}$ NMR spectra for compound 1}

Compound 1 exists as a pair of diastereoisomers since the porphyrins on the macrocycles can be on the same side or on the opposite side of the crown ether as shown below.

Tweezer 1 syn :

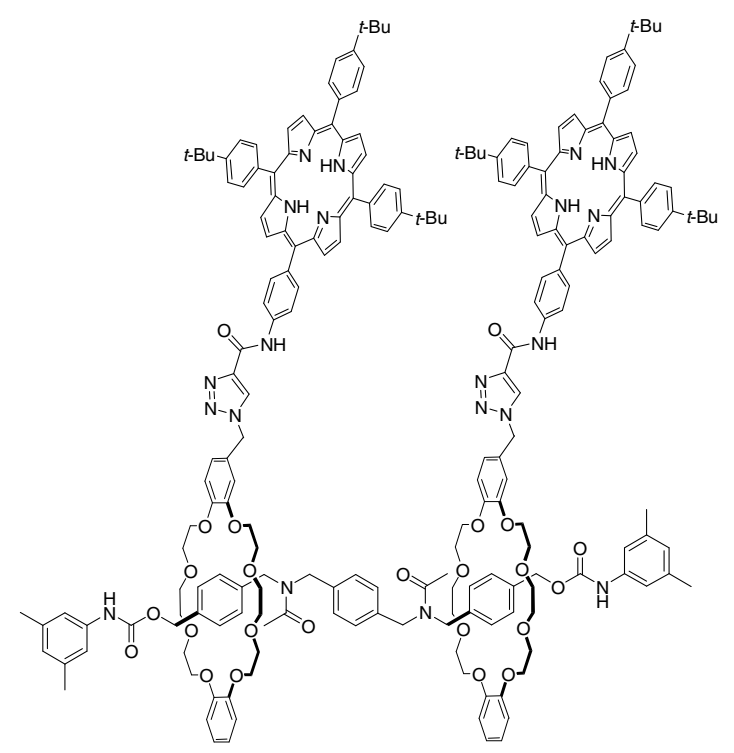

Tweezer 1 anti :

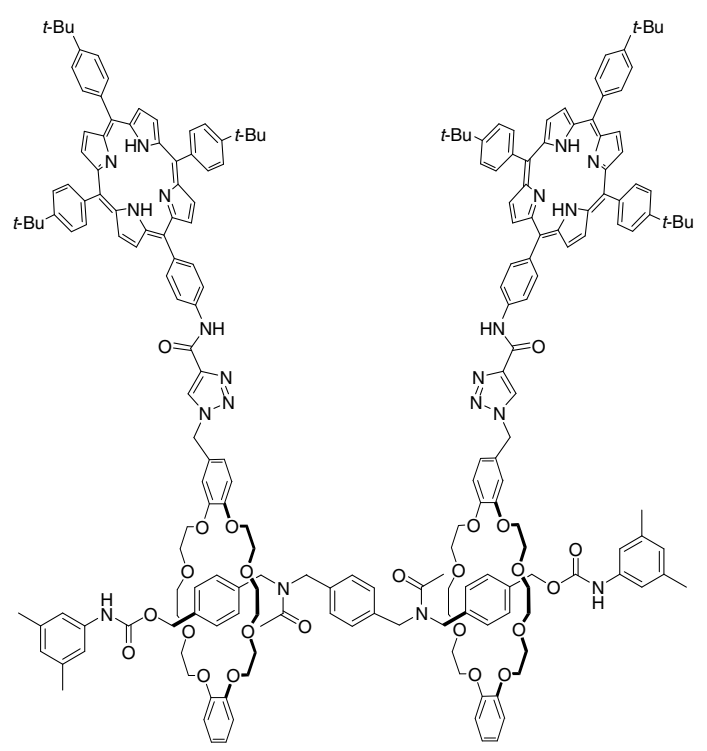


Tweezer (1). A $5 \mathrm{~mL}$ round bottom flask equipped with a magnetic stir bar was charged with $\mathbf{1 1}$ (26.0 mg, $0.015 \mathrm{mmol}), 6(50.9 \mathrm{mg}, 0.033 \mathrm{mmol}), \mathrm{CuBr}\left(\mathrm{PPh}_{3}\right)_{3}(5.40 \mathrm{mg}, 5.8 \mu \mathrm{mol})$, diisopropylethylamine (1 drop) and THF $(1.0 \mathrm{~mL})$. The resulting mixture was stirred for $72 \mathrm{~h}$ in the dark, poured into water and extracted twice with dichloromethane. The combined organic layers were washed once with water and dried over $\mathrm{MgSO}_{4}$. The solvent was removed under reduced pressure and the resulting dark red crude material was purified by column chromatography (silica gel, chloroform $100 \%$ followed by chloroform/acetone $4: 1$ as eluent) to provide $27 \mathrm{mg}$ of the title product as a dark red solid (53\%). M.P. dec. $>150{ }^{\circ} \mathrm{C}$. IR $(\mathrm{NaCl})$ : 2956; 1654; 1515; 1223; $1109 \mathrm{v} \mathrm{cm}^{-1} .{ }^{1} \mathrm{H}$ NMR (400MHz, $\left.\mathrm{CDCl}_{3}, \mathrm{ppm}\right): 9.37$ (s, 2H); 8.87 (s, 16H); 8.31 (m, 2H); $8.21(\mathrm{~m}, 4 \mathrm{H}) ; 8.12(\mathrm{~m}, 16 \mathrm{H}) ; 7.75(\mathrm{~m}, 12 \mathrm{H}) ; 7.29(\mathrm{~m}, 4 \mathrm{H}) ; 7.14(\mathrm{~m}, 6 \mathrm{H})$; $6.87(\mathrm{~m}, 22 \mathrm{H}) ; 6.54(\mathrm{~d}, 2 \mathrm{H}, J=4.9 \mathrm{~Hz}) ; 5.63(\mathrm{~m}, 4 \mathrm{H}) ; 5.44(\mathrm{~s}, 2 \mathrm{H}) ; 4.50(\mathrm{~m}, 4 \mathrm{H}) ; 4.30(\mathrm{~m}, 4 \mathrm{H})$; $4.12(\mathrm{~m}, 16 \mathrm{H}) ; 3.82(\mathrm{~m}, 16 \mathrm{H}) ; 3.46(\mathrm{~m}, 18 \mathrm{H}) ; 2.14(\mathrm{~m}, 18 \mathrm{H}) ; 1.60(\mathrm{~m}, 54 \mathrm{H}) ;-2.75(\mathrm{~s}, 4 \mathrm{H}) .{ }^{13} \mathrm{C}$ NMR (100 MHz, $\left.\mathrm{CDCl}_{3}, \mathrm{ppm}\right): 171.3 ; 158.3 ; 154.0 ; 150.6 ; 149.3 ; 149.2 ; 148.5 ; 148.4 ; 143.89$; 143.86; 139.63; 139.60; 139.33; 139.29; 138.61; 138.59; 138.38; 138.34; 138.28; 137.3; 136.7; $135.4 ; 134.65 ; 134.63 ; 128.9 ; 128.60 ; 128.56 ; 127.92 ; 127.90 ; 127.88 ; 127.65 ; 127.58 ; 126.8 ;$ $125.96 ; 125.90 ; 125.85 ; 123.8 ; 123.6 ; 121.08 ; 121.05 ; 120.94 ; 120.86 ; 120.5 ; 120.4 ; 119.3$; $118.23 ; 115.65 ; 115.62 ; 112.21 ; 112.17 ; 112.09 ; 112.05 ; 112.00 ; 111.9 ; 77.4 ; 70.03 ; 69.99 ;$ $69.95 ; 69.90 ; 69.8 ; 69.67 ; 68.55 ; 68.53 ; 68.1 ; 54.7 ; 51.0 ; 47.7 ; 35.0 ; 32.1 ; 31.8 ; 31.7 ; 29.85$; $29.80 ; 29.7 ; 29.6 ; 29.5 ; 29.4 ; 29.2 ; 24.9 ; 22.8 ; 21.88 ; 21.85 ; 21.50 ; 21.48 ; 14.3$. HRMS: Calculated for $\mathrm{C}_{214} \mathrm{H}_{226} \mathrm{~N}_{20} \mathrm{O}_{24}: 3460.7152[\mathrm{M}+\mathrm{H}]^{+}$. Found: 3460.6996. 

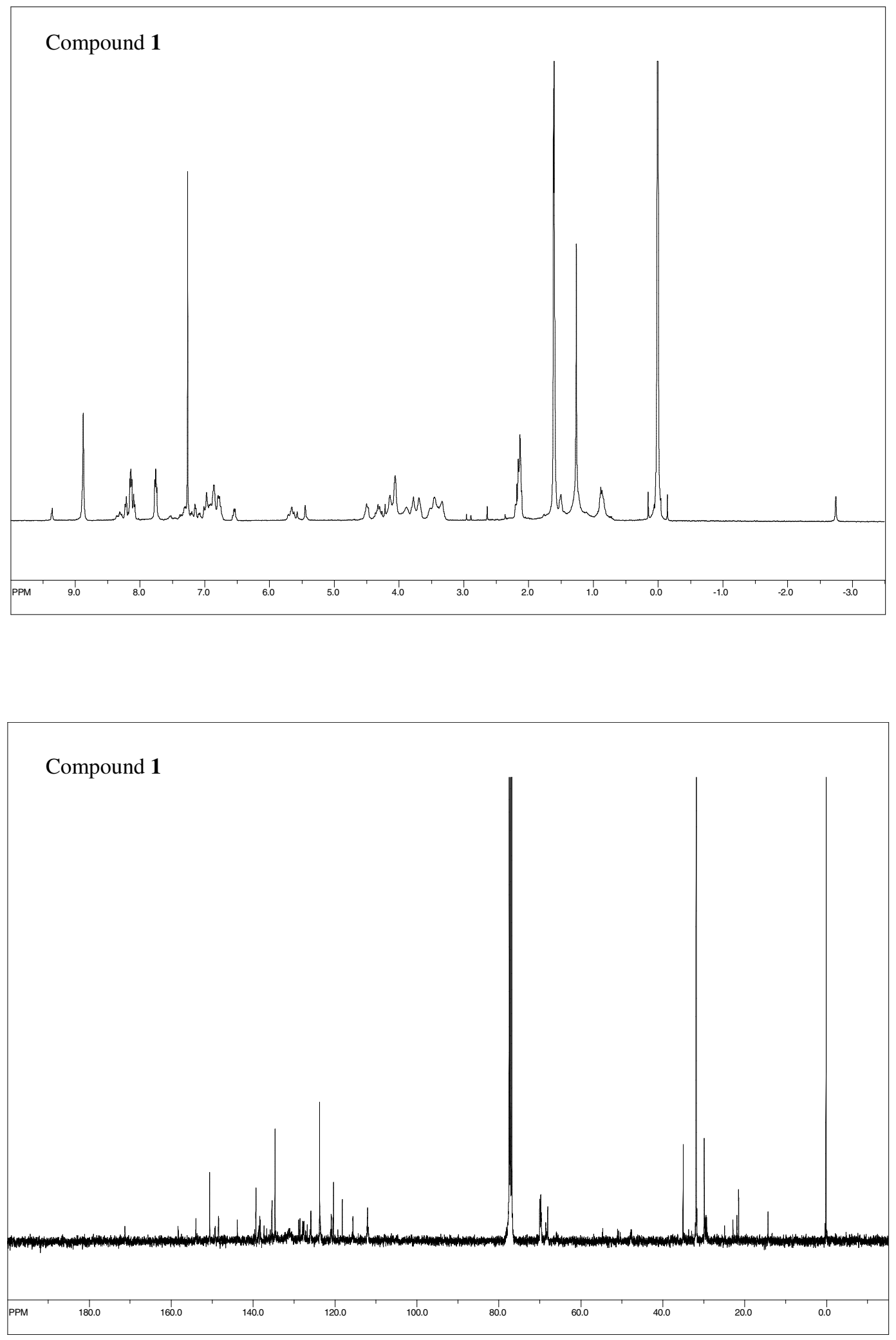


\section{Experimental data for compounds 1, 5-6, 8, 10-11}

General Synthetic Methods. ${ }^{1} \mathrm{H}$ and ${ }^{13} \mathrm{C}$ NMR spectra were recorded on a Varian AS400 apparatus in appropriate deuterated solvent solution at $298 \mathrm{~K}$. Chemical shifts were reported as $\delta$ values (ppm) relative to internal tetramethylsilane. High resolution mass spectroscopy (HRMS) was performed on a Agilent model 62-10 MS-TOF. IR spectra were obtained on a Bomem model MB-100 FTIR. UV-visible absorption spectra were recorded on a Varian diode-array spectrophotometer (model Cary 500) using 1-cm path length quartz cells. The fluorescence spectra were measured using a Varian Eclipse spectrofluorimeter. Reagent grade tetrahydrofuran (THF) was distilled over sodium benzophenone ketyl while dichloromethane $\left(\mathrm{CH}_{2} \mathrm{Cl}_{2}\right)$ and acetonitrile $\left(\mathrm{CH}_{3} \mathrm{CN}\right)$ were distilled under nitrogen over calcium hydride. All other reagents were purchased from commercial suppliers and used without further purification. Flash chromatography was carried out using silica gel (40-63 $\mu \mathrm{m}$ purchased from Silicycle). Thin layer chromatography (TLC) was carried out on glass plates coated with silica gel F-254 purchased from Silicycle. Compounds 7 and 9 were prepared using literature procedures. ${ }^{2,3}$

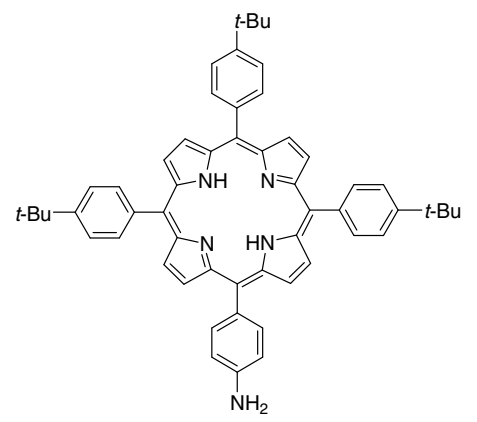

5-(para-aminophenyl)-10,15,20-tris-(4-tert-butylphenyl)porphyrin (5). An oven-dried $1 \mathrm{~L}$ round bottom flask equipped with a magnetic stir bar was charged with $p$ acetamidobenzaldehyde (970 mg, $5.94 \mathrm{mmol})$, 4-tert-butylbenzaldehyde (2.74 g, $16.9 \mathrm{mmol})$, freshly distilled pyrrole $(1.55 \mathrm{~g}, 23.1 \mathrm{mmol})$ and dry chloroform $(600 \mathrm{~mL})$. The solution was degassed in the dark using a flow of nitrogen for $30 \mathrm{~min} . \mathrm{BF}_{3} \cdot \mathrm{Et}_{2} \mathrm{O}(89 \mathrm{mg}, 0.45 \mathrm{mmol})$ was 
then added and the resulting mixture was stirred at room temperature for $2 \mathrm{~h}$ in the dark. Chloranil (1.15 g, $4.67 \mathrm{mmol})$ was added and the mixture was allowed to stir overnight at room temperature in the dark. The solvent was removed under reduce pressure and the crude material was pre-purified by column chromatography (silica gel, toluene followed by toluene:ethyl acetate $4: 1$ as eluent). The mixture containing ca. $80 \%$ of the acetyl-protected porphyrin was precipitated in methanol from a concentrated chloroform solution. The precipitate was collected by filtration and dried under vacuum for $24 \mathrm{~h}$ to provide $307 \mathrm{mg}$ of a purple powder that was used in the next step without further purification. For the amine deprotection, the purple powder was suspended in $\mathrm{HCl} 6 \mathrm{M}$ and heated to reflux overnight. The green mixture was cooled at $0^{\circ} \mathrm{C}$ and $\mathrm{KOH}$ pellets were added slowly until $\mathrm{pH}$ reached 11 . The suspension was extracted twice with dichloromethane and dried over $\mathrm{MgSO}_{4}$. The solvent was removed under reduced pressure and the crude material was purified by column chromatography (silica gel, dichloromethane as eluent) to provide $290 \mathrm{mg}$ of the title product as a purple powder (7\% for two steps). M.P. $>260$ ${ }^{\circ} \mathrm{C}$. IR (NaCl): v 3388, 2961, 1619, 966, $803 \mathrm{~cm}^{-1} .{ }^{1} \mathrm{H} \mathrm{NMR}\left(400 \mathrm{MHz}, \mathrm{CDCl}_{3}, \mathrm{ppm}\right): 8.91$ (d, $2 \mathrm{H}, J=4.5 \mathrm{~Hz}) ; 8.86(\mathrm{~m}, 6 \mathrm{H}) ; 8.13(\mathrm{~d}, 6 \mathrm{H}, J=7.9 \mathrm{~Hz}) ; 7.97(\mathrm{~d}, 2 \mathrm{H}, J=8.0 \mathrm{~Hz}) ; 7,74(\mathrm{~d}, 6 \mathrm{H}, J$ $=8.0 \mathrm{~Hz}) ; 6.99(\mathrm{~d}, 2 \mathrm{H}, J=7.4 \mathrm{~Hz}) ; 3.91(\mathrm{br} \mathrm{s}, 2 \mathrm{H}) ; 1.59(\mathrm{~s}, 27 \mathrm{H}) ;-2.72(\mathrm{~s}, 2 \mathrm{H}) .{ }^{13} \mathrm{C} \mathrm{NMR}(100$ $\left.\mathrm{MHz}, \mathrm{CDCl}_{3}, \mathrm{ppm}\right): 150.6 ; 146.1 ; 139.5 ; 139.4 ; 135.9 ; 132.7 ; 131,16 ; 123.7 ; 120.7 ; 120.2$; 120.1; 113.6; 35.0; 31.9; 31.8; 29.9. HRMS: Calculated for $\mathrm{C}_{56} \mathrm{H}_{55} \mathrm{~N}_{5}: 798.4530[\mathrm{M}+\mathrm{H}]^{+}$. Found: 798.4522. 


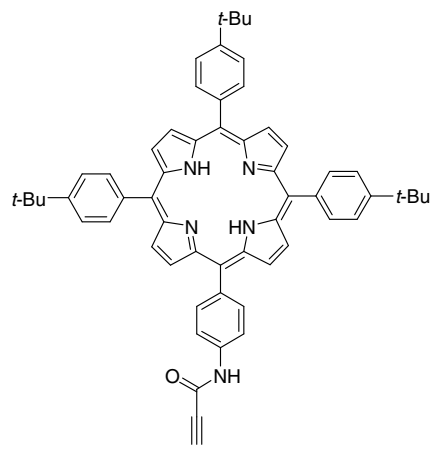

\section{5-(para-N-phenyl-2-propynamide)-10,15,20-tris-(4-tert-butylphenyl)porphyrin (6). A 50}

$\mathrm{mL}$ round bottom flask equipped with a magnetic stir bar was charged with 5 (190 mg, 0.24 mmol), propiolic acid (18.9 mg, $0.27 \mathrm{mmol})$, dicyclocarbodiimide (DCC) $(54.0 \mathrm{mg}, 0.26 \mathrm{mmol}$ ), 4-(dimethylamino)pyridine (DMAP) $(2.9 \mathrm{mg}, 0.02 \mathrm{mmol})$ and dichloromethane $(30 \mathrm{~mL})$. The mixture was stirred overnight at room temperature and the reaction was stopped by addition of water. The organic layer was washed three times with water and dried over $\mathrm{MgSO}_{4}$. The solvent was removed under reduce pressure and the resulting purple solid was purified by column chromatography (silica gel, dichloromethane/hexanes 4:1 followed by dichloromethane as eluent) to provide $122 \mathrm{mg}$ of the title product as a purple solid $(60 \%)$. M.P. $>260^{\circ} \mathrm{C}$. $\mathrm{IR}(\mathrm{NaCl})$ : v $3415,2957,1648,967,800 \mathrm{~cm}^{-1} .{ }^{1} \mathrm{H}$ NMR $\left(400 \mathrm{MHz}, \mathrm{CDCl}_{3}, \mathrm{ppm}\right): 8.88(\mathrm{~m}, 6 \mathrm{H}) ; 8.81(\mathrm{~d}$, $2 \mathrm{H}, J=4,5 \mathrm{~Hz}) ; 8.20(\mathrm{~d}, 2 \mathrm{H}, J=7.3 \mathrm{~Hz}) ; 8.14(\mathrm{~d}, 6 \mathrm{H}, J=6.0 \mathrm{~Hz}) ; 7.91(\mathrm{~d}, 2 \mathrm{H}, J=8.2 \mathrm{~Hz})$; $7.84(\mathrm{~s}, 1 \mathrm{H}) ; 7.76(\mathrm{~d}, 6 \mathrm{H}, J=7,8 \mathrm{~Hz}) ; 3.05(\mathrm{~s}, 1 \mathrm{H}) ; 1.61(\mathrm{~s}, 27 \mathrm{H}) ;-2.76(\mathrm{~s}, 2 \mathrm{H}) .{ }^{13} \mathrm{C} \mathrm{NMR} *(100$ $\left.\mathrm{MHz}, \mathrm{CDCl}_{3}, \mathrm{ppm}\right): 150.7 ; 150.0 ; 139.5 ; 139.31 ; 139.27 ; 135.4 ; 134.7 ; 134.6 ; 123.77 ; 123.75 ;$ 120.6; $120.5 ; 118.8 ; 118.3 ; 35.1 ; 31.8 ; 29.9$. HRMS: Calculated for $\mathrm{C}_{59} \mathrm{H}_{55} \mathrm{~N}_{5} \mathrm{O}: 850.4479[\mathrm{M}+$ H] $]^{+}$. Found: 850.4472 .

* Alkyne peaks are hidden in the residual chloroform peaks.

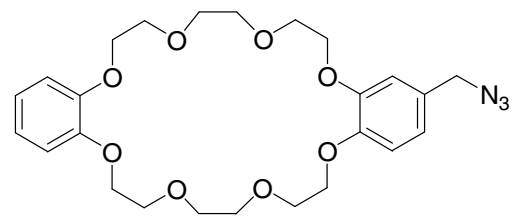


(2-azidomethyl)dibenzo[24]crown-8 (8). An oven-dried $25 \mathrm{~mL}$ round bottom flask equipped with a magnetic stir bar was charged with $7^{2}(330 \quad \mathrm{mg}, \quad 0.69 \mathrm{mmol}), \quad 1,8-$ diazabicyclo[5.4.0]undec-7-ene (DBU) (131 mg, $0.86 \mathrm{mmol})$, diphenylphosphoryl azide (DPPA) (238 mg, $0.86 \mathrm{mmol})$ and DMF $(7 \mathrm{~mL})$. The mixture was stirred for $16 \mathrm{~h}$ at room temperature. The solution was poured in water and extracted twice with chloroform. The combined organic layers were washed several times with water and dried over $\mathrm{MgSO}_{4}$. The solvent was removed under reduced pressure and the resulting orange oil was purified by column chromatography (silica gel, ethyl acetate as eluent) to provide $135 \mathrm{mg}$ of the title product as a white solid (39 \%). M.P. $72-74{ }^{\circ} \mathrm{C}$. IR (NaCl): v 2099, 1507, 1256, 1126, $746 \mathrm{~cm}^{-1}$. ${ }^{1} \mathrm{H}$ NMR (400MHz, $\left.\mathrm{CDCl}_{3}, \mathrm{ppm}\right): 6.88(\mathrm{~m}, 4 \mathrm{H}) ; 6.83(\mathrm{~m}, 3 \mathrm{H}) ; 4.23(\mathrm{~s}, 2 \mathrm{H}) ; 4.15(\mathrm{~m}, 8 \mathrm{H}) ; 3.92$ $(\mathrm{m}, 8 \mathrm{H}) ; 3.83$ (s, 8H). ${ }^{13} \mathrm{C}$ NMR (100 MHz, $\left.\mathrm{CDCl}_{3}, \mathrm{ppm}\right): 149.2 ; 149.1 ; 149.0 ; 128.4 ; 121.5$; 121.4; $114.1 ; 114.0 ; 113.8 ; 71,5 ; 71,4 ; 70.1 ; 70.0 ; 69.61 ; 69.59 ; 69.52 ; 54.8$. HRMS: Calculated for $\mathrm{C}_{25} \mathrm{H}_{33} \mathrm{~N}_{3} \mathrm{O}_{8}: 526.2160[\mathrm{M}+\mathrm{Na}]^{+}$. Found: 526.2159.

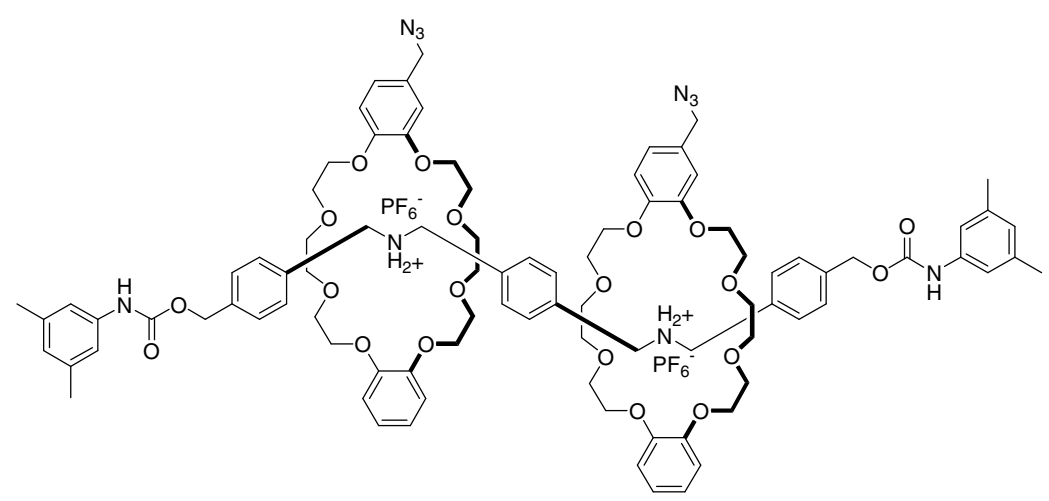

[3]Rotaxane (10). A $25 \mathrm{~mL}$ round bottom flask equipped with a magnetic stir bar was charged with 8 (114 mg, $0.23 \mathrm{mmol}), \mathbf{9}^{3}(69 \mathrm{mg}, 0.10 \mathrm{mmol})$, acetonitrile $(0.3 \mathrm{~mL})$ and dichloromethane (0.3 mL). After $1 \mathrm{~h}, 3,5$-dimethylphenylisocyanate $(45.0 \mathrm{mg}, 0.31 \mathrm{mmol})$ and dibutyltin dilaurate $(6.5 \mathrm{mg}, 0.01 \mathrm{mmol})$ were added. The mixture was stirred for $24 \mathrm{~h}$ at room temperature. The solvent was removed under reduce pressure and the crude material was 
purified by column chromatography (silica gel, chloroform $100 \%$ followed by chloroform/acetone 3:1 as eluent) to provide $108 \mathrm{mg}$ of the title product as a white solid (53\%). This molecule, as all of the following [3]rotaxanes, exists as a pair of diastereoisomers since the azide group on the macrocycles can be on the same side or on the opposite side of the crown ether (see p.S9 of Supporting Information). M.P. dec. > $99{ }^{\circ} \mathrm{C} . \mathrm{IR}(\mathrm{NaCl})$ : v 3397 , 2099, 1505, 1219, $842 \mathrm{~cm}^{-1} .{ }^{1} \mathrm{H}$ NMR (400MHz, $\left.\mathrm{CDCl}_{3}, \mathrm{ppm}\right): 7.50$ (br s, 4H); 7.24 (dd, 8H, $J$ = 29.8 and $7.8 \mathrm{~Hz}) ; 7.06(\mathrm{~m}, 8 \mathrm{H}) ; 6.94(\mathrm{~s}, 2 \mathrm{H}) ; 6.69(\mathrm{~m}, 16 \mathrm{H}) ; 5.04(\mathrm{~s}, 4 \mathrm{H}) ; 4.67$ (br s, 4H); 4.39 (br s, 4H); $4.21(\mathrm{~s}, 4 \mathrm{H}) ; 4.00(\mathrm{~m}, 16 \mathrm{H}) ; 3.64(\mathrm{~m}, 32 \mathrm{H}) ; 3.35(\mathrm{~s}, 12 \mathrm{H}) .{ }^{13} \mathrm{C} \mathrm{NMR}(100 \mathrm{MHz}$, $\left.\mathrm{CDCl}_{3}, \mathrm{ppm}\right): 153.3 ; 147,6 ; 147.48 ; 147.45 ; 147.2 ; 138.8 ; 137.7 ; 137.5 ; 132.4 ; 131.7 ; 129.9$; $129.2 ; 128.6 ; 128.0 ; 125.3 ; 121.4 ; 121.3 ; 116.4 ; 112.7 ; 112.6 ; 112.52 ; 112.45 ; 112.41 ; 70.89$; $70.87 ; 70.77 ; 70.74 ; 70.27 ; 70.24 ; 68.2$ to $67.7 * ; 65.9 ; 54.3 ; 52.2 ; 52.0 ; 29.8 ; 21.4$. HRMS: Calculated for $\mathrm{C}_{92} \mathrm{H}_{114} \mathrm{~F}_{12} \mathrm{~N}_{10} \mathrm{O}_{20} \mathrm{P}_{2}: 1676.8010\left[\mathrm{M}-2 \mathrm{PF}_{6}+\mathrm{H}\right]^{+}$. Found: 1676.8054, Calculated for $\mathrm{C}_{92} \mathrm{H}_{114} \mathrm{~F}_{12} \mathrm{~N}_{10} \mathrm{O}_{20} \mathrm{P}_{2}: 1822.7774\left[\mathrm{M}-\mathrm{HPF}_{6}+\mathrm{H}\right]^{+}$. Found: 1822.7736

* The number of carbon in this signal cannot be measured precisely.

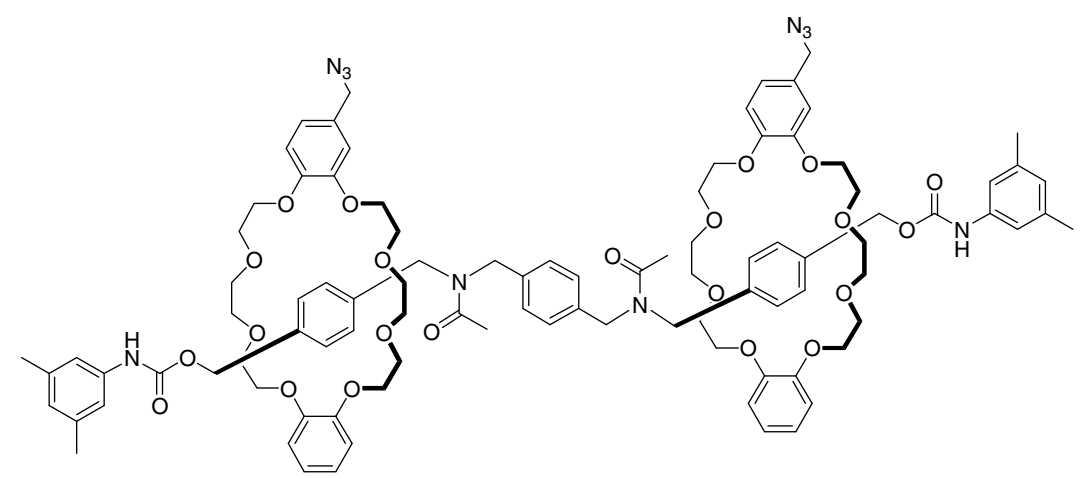

[3]Rotaxane (11). A $25 \mathrm{~mL}$ round bottom flask equipped with a magnetic stir bar was charged with $10(75 \mathrm{mg}, 0.04 \mathrm{mmol})$, acetic anhydride $(39.0 \mathrm{mg}, 0.38 \mathrm{mmol})$, triethylamine $(39.0 \mathrm{mg}$, $0.38 \mathrm{mmol})$ and acetonitrile $(2 \mathrm{~mL})$. The solution was stirred at $40^{\circ} \mathrm{C}$ for $48 \mathrm{~h}$ and then cooled at room temperature. The white precipitate was filtered, rinsed with acetonitrile and dried under 
reduce pressure for $24 \mathrm{~h}$ to provide $54 \mathrm{mg}$ of the title product as a white solid (81\%). M.P. 183$186{ }^{\circ} \mathrm{C} . \mathrm{IR}(\mathrm{NaCl}): 2099,1557,1226,1127,754 \cup \mathrm{cm}^{-1} .{ }^{1} \mathrm{H}$ NMR $\left(400 \mathrm{MHz}, \mathrm{CDCl}_{3}, \mathrm{ppm}\right): 8.35$ $(\mathrm{d}, 2 \mathrm{H}, J=12.0 \mathrm{~Hz}) ; 7.32(\mathrm{~m}, 4 \mathrm{H}) ; 7.19(\mathrm{~d}, 2 \mathrm{H}, J=7.9 \mathrm{~Hz}) ; 7.13(\mathrm{~m}, 2 \mathrm{H}) ; 7.07(\mathrm{~d}, 2 \mathrm{H}, J=7.9$ $\mathrm{Hz}) ; 6.91(\mathrm{~m}, 20 \mathrm{H}) ; 6.54(\mathrm{~d}, 2 \mathrm{H}, J=7.0 \mathrm{~Hz}) ; 5.69(\mathrm{~m}, 4 \mathrm{H}) ; 4.49(\mathrm{~m}, 4 \mathrm{H}) ; 4.32(\mathrm{~m}, 4 \mathrm{H}) ; 4.26(\mathrm{~s}$, 4H); $4.14(\mathrm{~m}, 16 \mathrm{H}) ; 3.91(\mathrm{~m}, 8 \mathrm{H}), 3.75(\mathrm{~m}, 8 \mathrm{H}) ; 3.51(\mathrm{~m}, 8 \mathrm{H}) ; 3.39(\mathrm{~m}, 8 \mathrm{H}) ; 2.15(\mathrm{~m}, 18 \mathrm{H})$. ${ }^{13} \mathrm{C}$ NMR $\left(100 \mathrm{MHz}, \mathrm{CDCl}_{3}, \mathrm{ppm}\right): 171.13 ; 171.09 ; 153.9 ; 148.80 ; 148.78 ; 148.68 ; 148.67 ;$ 148.52; 148.47; 139.6; 138.8; 138.7; 138.28; 138.21; 137.0; 136.6; 136.2; 135.7; 134.9; 134.0; $133.9 ; 128.8 ; 128.5 ; 127.75 ; 127.71 ; 127.68 ; 127.64 ; 127.4 ; 127.1 ; 126.7 ; 125.9 ; 123.53 ;$ $123.48 ; 120.90 ; 120.86 ; 120.82 ; 115.62 ; 115.58 ; 112.08 ; 112.04 ; 111.8 ; 77.4 ; 69.95 ; 69.92 ;$ $69.79 ; 69.74 ; 68.4 ; 68.1 ; 66.0 ; 65.8 ; 54.8 ; 50.8 ; 50.7 ; 50.27 ; 50.22 ; 47.73 ; 47.67 ; 47.55 ; 47.52 ;$ 29.8; 21.8; 21.42; 21.40. HRMS: Calculated for $\mathrm{C}_{96} \mathrm{H}_{116} \mathrm{~N}_{10} \mathrm{O}_{22}: 1761.8338[\mathrm{M}+\mathrm{H}]^{+}$. Found: 1761.8318. 


\section{4. ${ }^{1} \mathrm{H}$ and ${ }^{13} \mathrm{C}$ NMR spectra for compounds $1,5-6,8,10-11$}
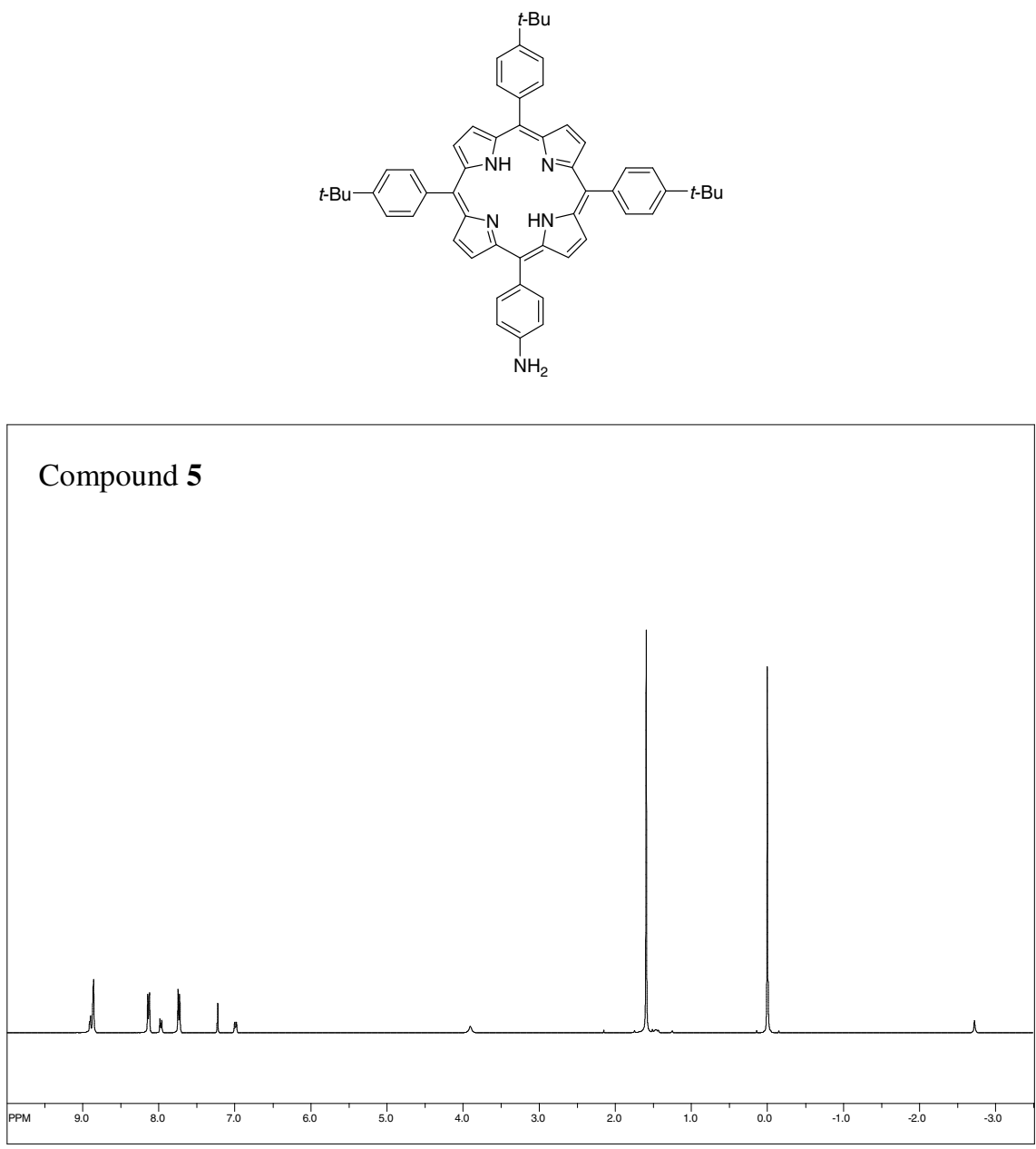

Compound 5

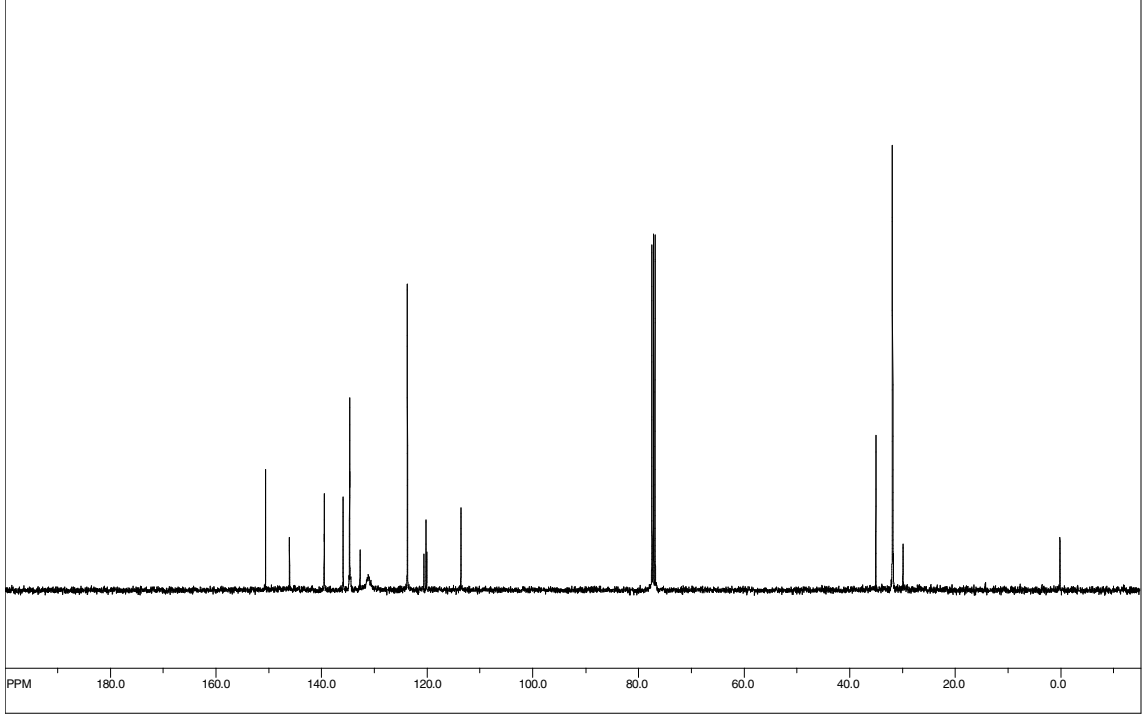



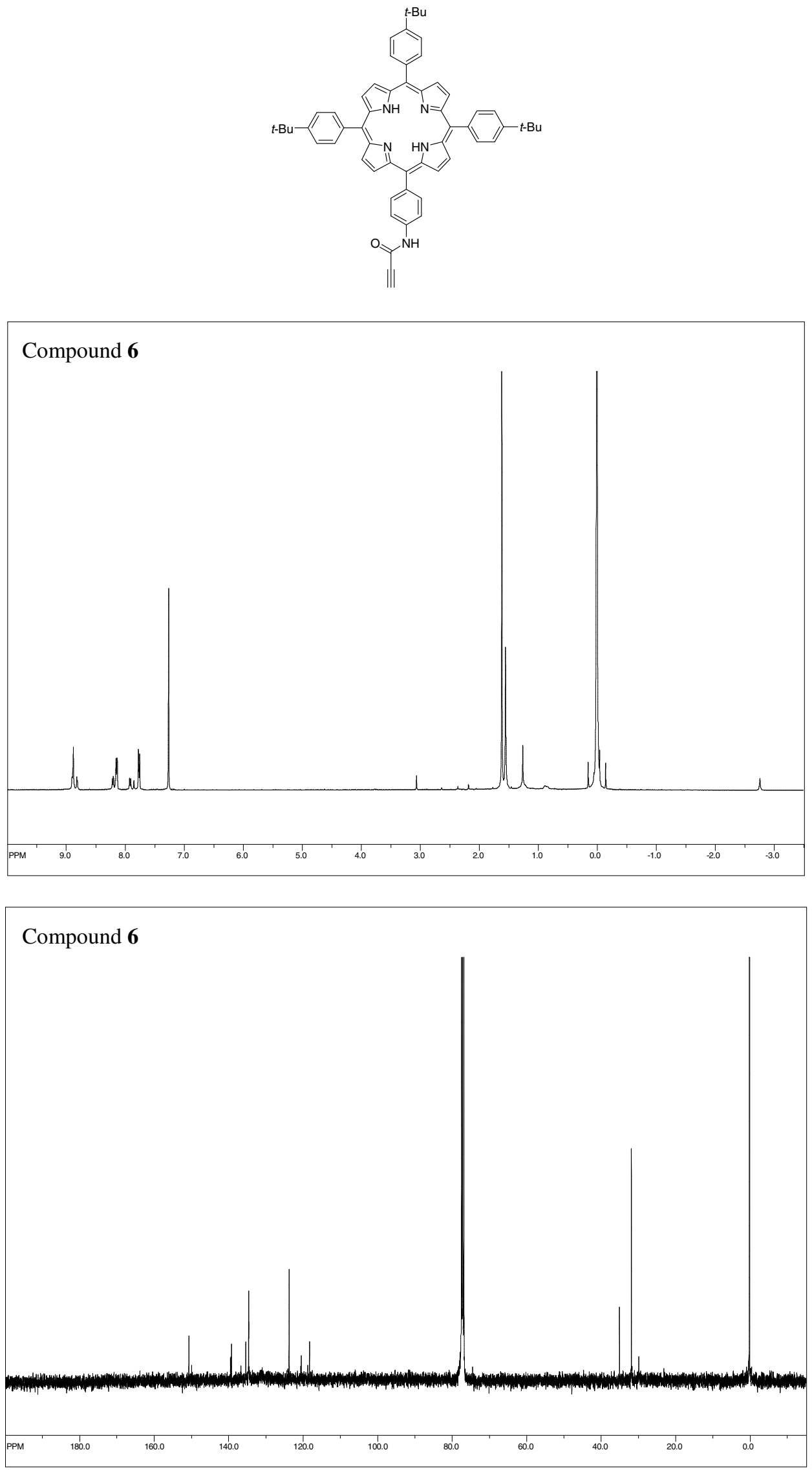

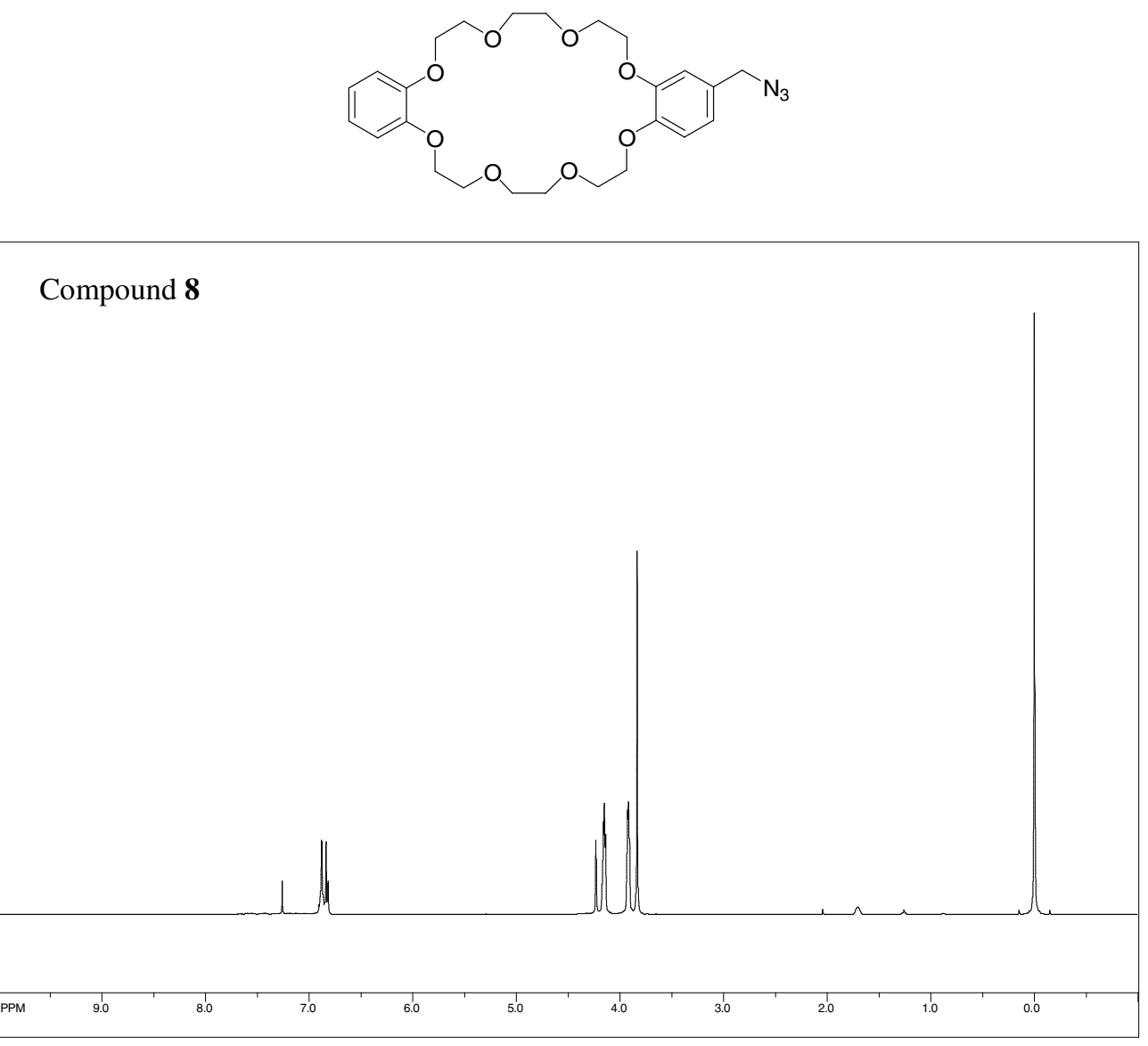

\section{Compound 8}

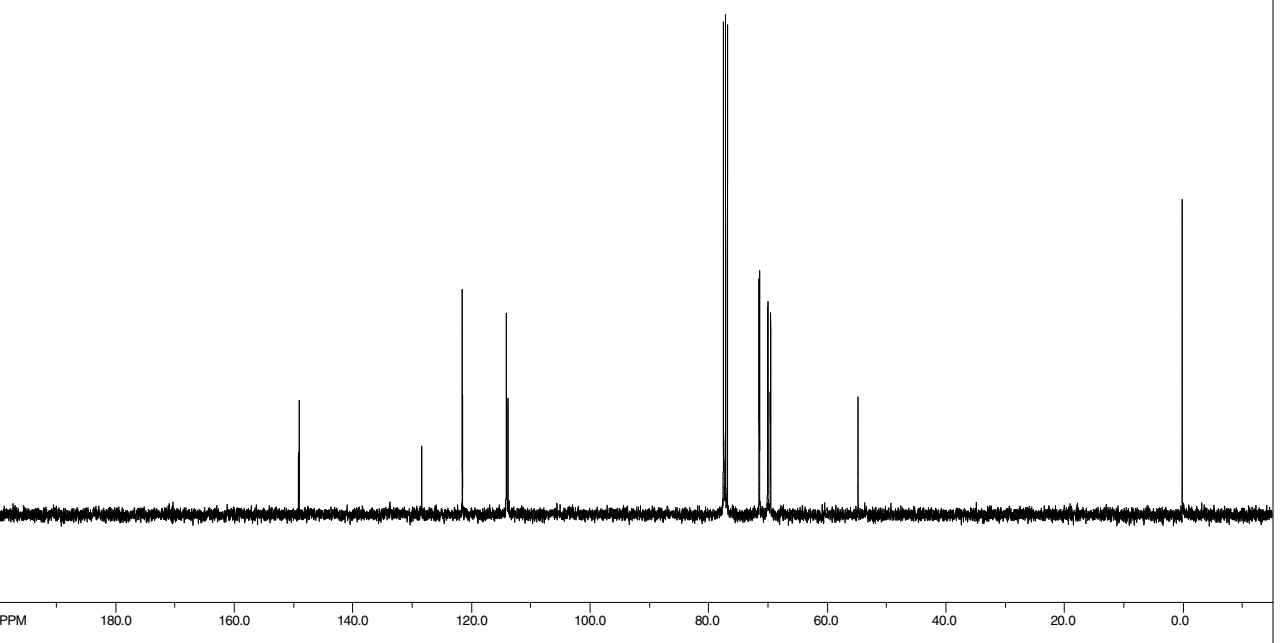



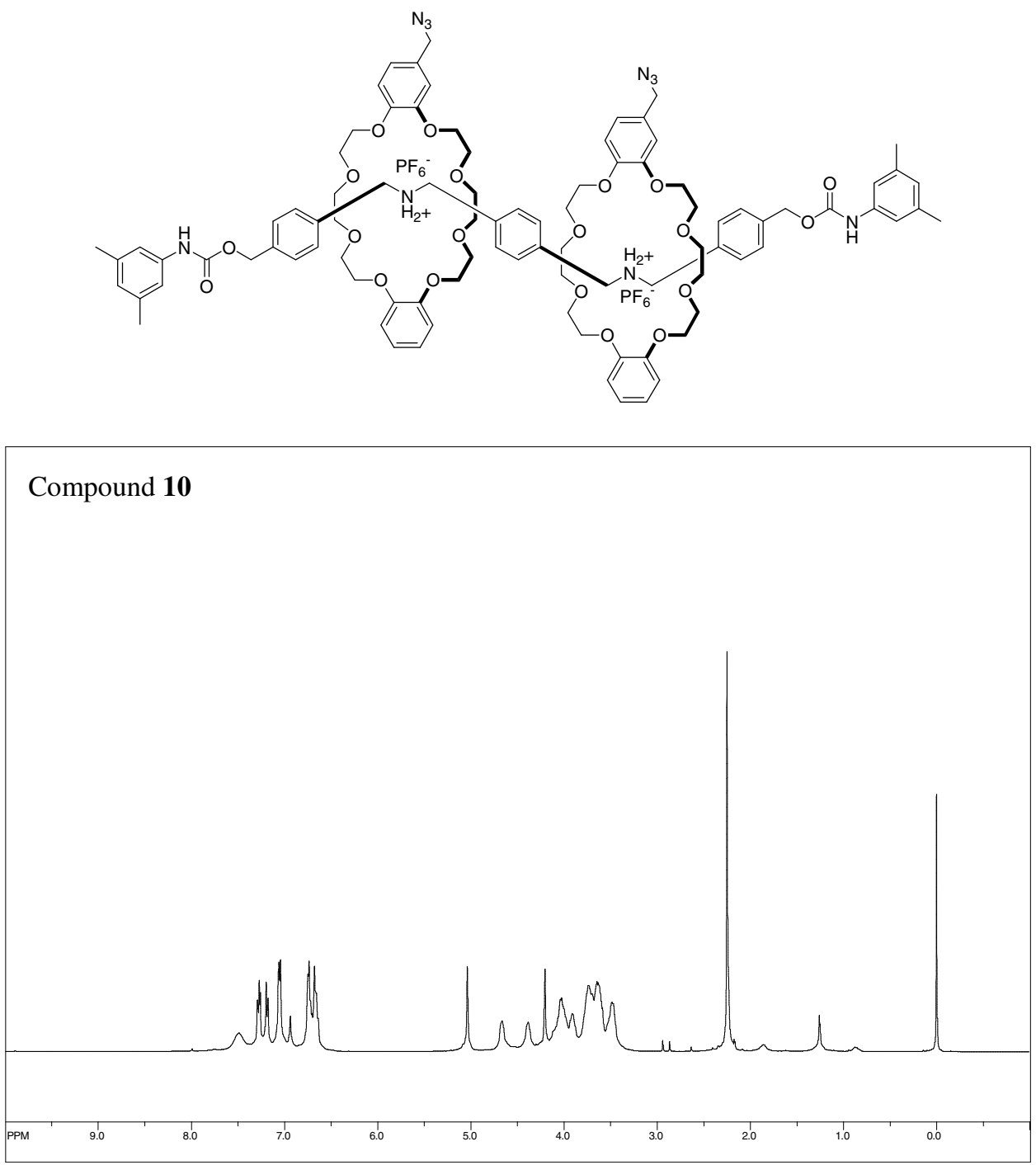

Compound 10

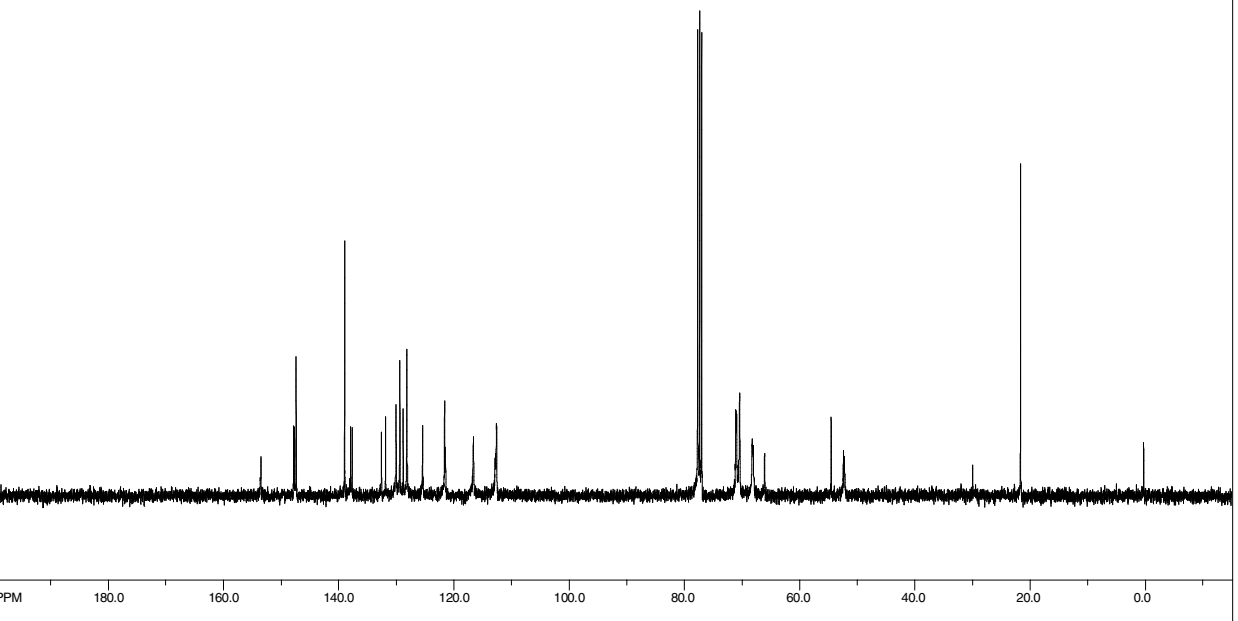



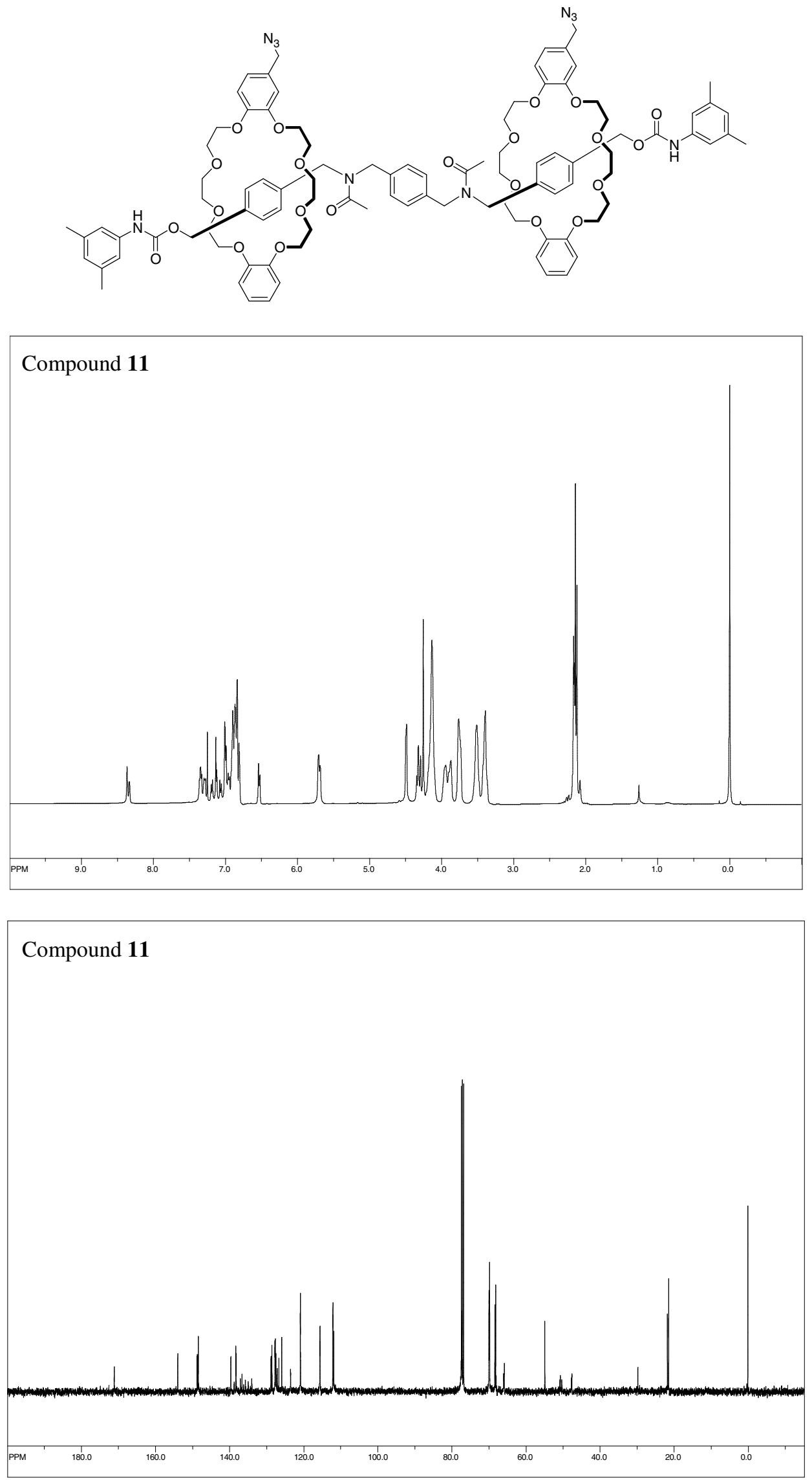


\section{References}

(1) Conors, K. A. Binding Constants: The Measurement of Molecular Complex Stability. John Wiley \& Sons: New York, NY, 1987.

(2) Fulton, D. A.; Cantrill, S. J.; Stoddart, J. F. J. Org. Chem. 2002, 67, 7968

(3) Furucho, Y.; Sasabe, H; Natsui, D.; Murakawa, K-I,; Takata, T; Harada, T. Bull. Chem. Soc. Jpn. 2004, 77, 179 